\title{
Employee Silence, Organizational Commitment, and Job Burnout of Regular Employees in Local Government Units in the Cotabato Province, Philippines: A Keystone for Intervention
}

\author{
Rowell P. Nitafan
}

Department of Social Science and Philosophy, University of Southern Mindanao, Philippines

Received: 7 Oct 2020; Received in revised form: 11 Nov 2020; Accepted: 16 Nov 2020; Available online: 22 Nov 2020 C2020 The Author(s). Published by Infogain Publication. This is an open access article under the CC BY license (https://creativecommons.org/licenses/by/4.0/).

\begin{abstract}
The study was a quantitative research that employed descriptive and correlational research designs. It primarily determined if there is a significant association between employee silence, organizational commitment, and job burnout of the regular employees of the selected local government units in District three (3) of the Cotabato province.

Results found out that the degree of employee silence in terms of acquiescent, quiescent, prosocial and opportunistic silence observed by the regular employees of the selected local government units at work was moderate. Furthermore, the findings showed that they also shared a moderate degree of organizational commitment in terms of affective, continuance and normative commitment towards their organization. Lastly, the study determined that they experienced a moderate degree of job burnout in terms of exhaustion, cynicism, and professional inefficacy at work.

Moreover, the research determined a positive yet very low relationship between employee silence and job burnout, while a negative and very low relationship between organizational commitment and job burnout of the regular employees. Lastly, it was verified in the study that none of the dimensions of employee silence and organizational commitment was statistically significantly linked with any of the dimensions of job burnout. Nevertheless, the study concluded that the correlations that were found between the variables and their dimensions were insignificant and statistically due to probability.

Making the study more meaningful for the research respondents, the study recommended an intervention program in the form of development training that the Heads, Supervisors and HRMDO of the concerned offices may use as a keystone in addressing the issues on job burnout that were identified in the study such as feeling strain from working all-day, emotionally drained from work, and used up at the end of the workday for exhaustion; becoming more cynical about the contributions of their work and less enthusiastic about work for cynicism; inability to solve the problems that arise at work, uncertainty on being effective in getting things done, and unable to feel happy when something was accomplished at work for professional inefficacy. Keywords - Employee silence, intervention program, local government units, job burnout, organizational commitment.
\end{abstract}

\section{INTRODUCTION}

In the world of management, it is a widely accepted fact that the employees are the sap of any organization. They primarily determine the fate of the organization. Hence, it is important that they are always motivated, committed and enthusiastic in their job to yield the best productive output for the organization. In the government, public service is a ISSN: 2456-7620

https://dx.doi.org/10.22161/ijels.56.20 demanding and exhausting job. The work overload, unnecessary work, lack of recognition, lack of control, lack of opportunity, dead time, and lack of trust were some of the depressing depictions of government workplaces (Mckenna, 2015).

Burnout is a widespread experience in working in the public sector. In fact, several studies show that government 
employees are at risk of job burnout (Boemah, 2006; Rothmann, Jackson \& Kruger, 2003; Van der Merwe, 1984). Burnout is regarded as a deteriorating factor in the health and productivity of the members of the organization. It is a mental condition defined as the body's reaction to occupational stress characterized by three (3) main dimensions - exhaustion, cynicism or depersonalization, and professional inefficacy (Maslach, Schaufeli, \& Leiter, 2001). The ever-increasing occupational stress exhausts the employees to the extent that their physical and emotional resources are depleted in their attempts to succeed the pressure of the job they work with other people. This leads them to lose motivation and other positive sentiments that otherwise result to feelings of incompetence and lack of accomplishment (Sabaah et al. 2012).

Furthermore, silence and voice have gained the interest of researchers for more than 50 years. Employees' voice is essential in maintaining a healthy workplace. It is integral in handling agreement, addressing conflicts, transmitting knowledge, and promoting innovation in the organization (Kumar, Alagappar \& Govindarajo, 2015). However, some employees refrain from voicing their ideas, opinions, and concerns about matters in their organization. This phenomenon is referred to as employee silence. Researchers explore the construct of employee silence using four (4) dimensions - acquiescent, quiescent, prosocial, and opportunistic silence (Morrison \& Milliken, 2000; Pinder \& Harlos, 2001; Knoll \& van Dick, 2013). While it is seen by many as a sign of loyalty, many studies have demonstrated that employee silence is destructive to the organization for it impedes innovation, increases resistance to organizational change, and exacerbates employees' feelings of stress and depression (Alparslan, Can \& Erdem, 2015; Argyris \& Schön, 1978; Morrison \& Milliken, 2000).

Moreover, organizational commitment has become a popular research topic in organizational management and organizational behavior (Cohen, 2014). Organizational commitment was defined by Grusky (1996) as "an individual's attachment to an organization." Özsoy et al. (2004) added that organizational commitment is about prioritizing the organization's interests rather than the individual's interests. McDonald and Makin (2000) described the organizational commitment as a contract between a person and an organization. Nevertheless, Meyer \& Allen (1997) developed a scale that measures organizational commitment and defined it as a multidimensional construct comprised of affective, continuance, and normative commitment.

Meanwhile, numerous studies have linked employee silence, organizational commitment, and job burnout. In fact, the studies of Paksirat \& Taheri (2016) \& Knoll, Hall
\& Weigelt (2018) found out that employee silence has a positive and direct significant relationship with job burnout. Additionally, it was determined by Leiter \& Maslach (1988) that job burnout is significantly correlated with organizational commitment. They further specified that all the dimensions of job burnout are associated with organizational commitment. However, in the conducted extensive literature review by the researcher in over 56 available researches online, it was determined that there was a vacuum of study in the Philippines that ventured to correlate employee silence, organizational commitment, and job burnout, especially among local government employees. It was in this light that the researcher conducted a study that filled-in the void in the body of research on employee silence, organizational commitment, and job burnout, particularly among the selected local government units in District three (3) of Cotabato.

\section{OBJECTIVES OF THE STUDY}

The study focused on the correlation between employee silence, organizational commitment, and job burnout among the selected local government units in District three (3) of Cotabato province.

Specifically, it endeavored to:

1. Determine the level of employee silence of the regular employees in the selected local government units in District three (3) of Cotabato province in terms of:

1.1. Acquiescent silence

1.2. Quiescent silence

1.3. Prosocial silence

1.4 Opportunistic silence

2. Determine the level of organizational commitment of the regular employees in terms of:

2.1. Affective commitment

2.2. Continuance commitment

2.3. Normative commitment

3. Determine the level of job burnout of the regular employees in terms of:

3.1. Exhaustion

3.2. Cynicism

3.3. Professional inefficacy

4. Determine if there is a significant relationship between employee silence and job burnout.

5. Determine if there is a significant relationship between organizational commitment and job burnout.

6. Recommend an intervention program that will address the issues or problems identified in the study pertinent to job burnout. 


\section{HYPOTHESES}

The following hypotheses were tested at 0.05 level of significance:

$\mathrm{H}_{0} 1$ : There is no significant relationship between the employee silence and job burnout of the regular employees in the selected local government units in District three (3) of Cotabato province.

$\mathrm{H}_{0} 2$ : There is no significant relationship between the organizational commitment and job burnout of the regular employees in the selected local government units in District three (3), Cotabato.

\section{CONCEPTUAL FRAMEWORK}

Figure one (1) presents the conceptual framework of the study. The model shows the relationship between employee silence, organizational commitment and job burnout among the regular employees of the selected local governments in the third congressional district of Cotabato province.

Furthermore, all of the variables being investigated in the study are all multidimensional viewed according to the most influential researchers in the field. Employee silence was studied using the construct of Knoll and van Dick (2013) which was characterized into four (4) dimensions namely acquiescent, quiescent, prosocial and opportunistic silence. Moreover, organizational commitment was determined using the dimensions provided by Meyer \& Allen (1997) which comprised affective, continuance, and normative commitment. Lastly, job burnout was determined through the dimensions of Maslach, Schaufeli, \& Leiter (2001) which involved exhaustion, cynicism and professional inefficacy.

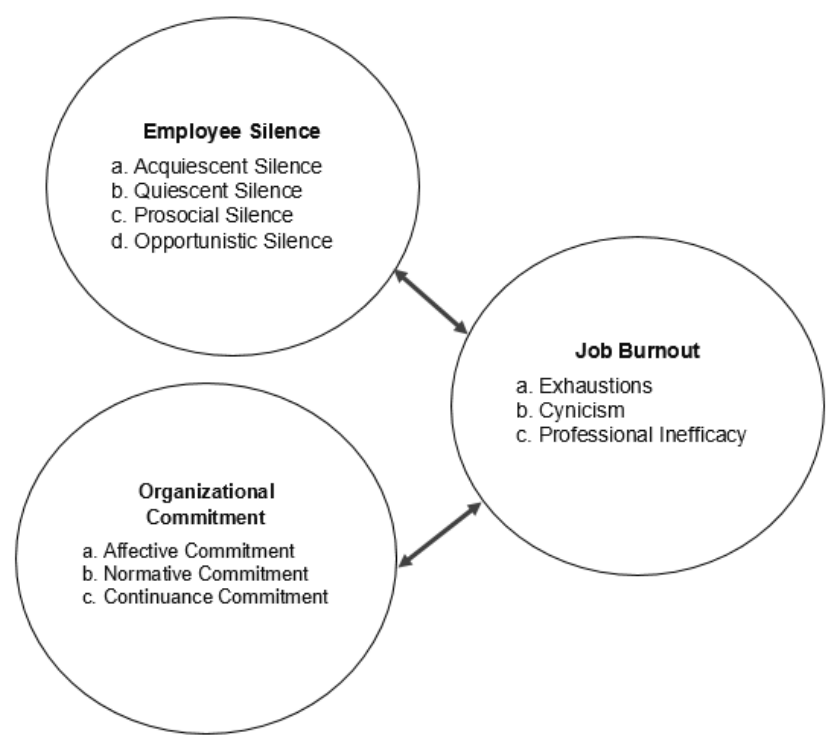

Fig.1: Conceptual Framework

\section{THEORETICAL FRAMEWORK}

Employee silence, organizational commitment and job burnout are long studied concepts in the field of public administration. The underlying assumptions of the theory can be grounded through a series of theories. In explicating employee silence, the spiral of silence theory and theory of reasoned action were used in the study. Moreover, the concept of organizational commitment is anchored on the Self-Categorization Theory of Turner (1999). Lastly, job burnout was elucidated through the multidimensional burnout model of Maslach, Schaufeli, \& Leiter (2001).

The spiral of silence theory was developed by Nuemann (1974) to refer to people's inclination to refrain from speaking when they feel that their ideas or opinions are contrary to view of majority. The theory postulates a notion that voicing an opinion may lead to an adverse consequence like reprisal or social isolation.

The study is also supported by the theory of reasoned action of Fishbein \& Ajzen (1980). This theory implies that the behaviour of an individual can be understood by delving into his personal intentions. Intention is the best determinant of behaviour. It is in turn shaped by (3) three factors attitude, personal norms, and ability to control behaviour. According to. A higher chance that the intention of the person will be executed into a behaviour if the attitude and subjective norms are more favourable to him/her, and there is a greater perceived control.

Furthermore, Knoll \& van Dick (2013) suggests that employees choose not to express their ideas, opinions or concerns related to their work due to four (4) factors. First, employees opt to be silent in the organization because they believe that speaking up is pointless because there is nobody to listen their constructive voice. Second, they fear that giving comments may be personally risky. Third, they believe that their silence is valuable to help or benefit their colleagues or the organization as a whole. Lastly, employees withhold their ideas because they have egoistic motives. Deduced from past studies and theories, they conceptualized the four (4) dimensions of employee silence which include acquiescent, quiescent, prosocial and opportunistic silence.

Moreover, the organizational commitment concept that was examined in the study can be rooted from the SelfCategorization Theory of Turner (1999). According to this theory, the self is formed through organizational ties and how people see themselves on different levels. This approach holds that, depending on how important the situation for social or personal identity, an individual's behaviour is developed by either by social or personal identity processes. The theory suggests that one can see himself as an individual, but connected with the social 
group to which he or she belongs. The person then becomes a subordinated individual whose identity is driven from the social connections that he or she has. The theory explains that organizational commitment is influenced by how a person develops his or her identity. It can be assumed that if a large part of his or her identity belongs to the group, then it can be expected that he or she has a larger organizational commitment.

Moreover, the multidimensional theory of burnout proposed by Maslach, Schaufeli, \& Leiter (2001) conceptualized job burnout into three (3) core components - exhaustion (the basic individual stress dimension), cynicism (the interpersonal dimension), and professional inefficacy (the self-evaluation dimension). According to their theory, exhaustion occurs when a person feels that his or her emotional and physical resources are overused and depleted, and there is no source to replenish them. They said that exhaustion is usually due to work overload and personal conflict at work. On the other hand, cynicism is characterized by feelings of detachment from work which then results to negative reaction to people and to the job. Lastly, professional inefficacy happens when a person feels incompetence, lack of personal accomplishment and reduced productivity at work. People experiencing this dimension feels that the choosing their job is a mistake, and often have negative view for themselves and for others.

On the other hand, several propositions were formulated by scholars in organizational sciences that determined the significant linkage between employee silence, organizational commitment and job burnout. In determining the significant linkage between employee silence and job burnout, Paksirat \& Taheri (2016) determined a significant inverse relationship between the two (2) constructs in the context of teachers. Secondly, Akin \& Ulusoy (2016) determined a positive correlation between the two (2) constructs in the context of university academicians. Thirdly, Mahmoud \& Muthana (2018) verified the significant effect of employee silence on the job burnout of hotel workers.

In examining the significant correlation between organizational commitment and job burnout, Leiter \& Maslach (1988) indicated that organizational commitment does not show a unique linkage with all of the components of job burnout although a significant correlation was determined between the two (2) constructs. Furthermore, Tan and Akhtar (1998) upon working from a cultural perspective, examined the relationships between normative and affective aspects of organizational commitment and experienced burnout among bank employees. They determined in their study that one of the dimensions of organizational commitment, particularly the normative commitment positively and significantly influences experienced burnout, whereas affective commitment had no significant influence. Meanwhile, a different result was shown by Sarışık, Boğan, Zengin \& Dedeoğlu (2019) who concluded that organizational commitment is negatively linked with job burnout.

\section{METHODOLOGY}

\section{Research Design}

This research was a quantitative research that employed a descriptive-correlational designs. Descriptive design was used to ascertain the level of employee silence in terms of acquiescent, quiescent, prosocial and opportunistic silence, organizational commitment in terms of affective, continuance and normative commitment and job burnout in terms of exhaustion, cynicism, and professional efficacy of the regular employees in the selected local government units in District three (3), Cotabato. On the other hand, correlational design was used to determine if there is significant relationship between the employee silence, organizational commitment and employee's job burnout among the government employees in the selected government units in the province of Cotabato.

\section{Research Locale}

The study was conducted in the selected local government units (LGU) in the third district of Cotabato province which comprise the municipality of Kabacan, Matalam, and Carmen. According to the Commission on Elections (2016) of the province of Cotabato, the third legislative district of Cotabato province comprise the municipality of Banisilan, Carmen, Kabacan, Matalam, Mlang, and Tulunan. However, the conduct of the study was limited to the selected three (3) municipalities due to the following reasons:

1. They are first class municipalities in terms of income compared to the other municipalities in the third congressional district of Cotabato province (Philippine Statistics Authority, 2019):

2. They are the most populated municipalities (Philippine Statistics Authority, 2019):

3. They are the most accessible municipalities to the researcher. It will make the conduct of the study feasible and less costly to the researcher.

\section{Respondents of the Study}

The respondents of the study were 236 regular employees in the selected offices of the local government units (LGU) of Kabacan, Matalam and Carmen, Cotabato. Particularly, the selected offices comprised the Municipal Civil Registrar's Office, Municipal Accountant's Office, Municipal Treasurer's Office, Human Resource Management Office, Municipal Budget Office, Municipal 
Planning and Development Office, Municipal Social Welfare Development Office, Municipal Disaster, Risk Reduction Management's Office, Municipal Engineer's Office, and Municipal of Health Office. These were chosen since they were recorded to be some of the most demanding offices, and employees working in these offices are at high risk of job burnout (Cooke, Doust, \& Steele, 2013; Takeda, Yokoyama, Ibaraki, 2005; Yau \& Chong, 2019).

Moreover, they were identified through the following criteria:

1. They shall be permanent government employees who met all the requirements for the position to which he or she is appointed:

2. They shall be rank-and-file employees:

3. They shall have worked in the office where he or she is designated for at least one (1) year.

\section{Sampling Method}

The respondents of the study were the regular government employees in the selected local government units in the third legislative district of Cotabato province. In determining the study sample, non-probability convenience sampling was employed by the researcher. In the identifying the research respondents, the author was guided by several criteria in accordance with the objectives of the study, but conducted the study in accordance with the availability of the regular employees to participate in the research. The researcher acknowledged the non-probability errors that arose in the study such as not getting the complete number of employees in every identified office considering their heavy workloads and busy schedules.

\section{Instrumentation}

The instrument that was used in this research was a survey questionnaire that was divided into four (4) parts. The first part obtained data on the profile of the respondents; the second part focused on the level of employee silence; the third part measured the level of organizational commitment, and the fourth part determined the work burnout of local government employees in the selected municipalities in the Cotabato province. All was modified from several studies.

On the aspect of employee silence, the researcher modified a questionnaire from the study Alparslan, Erdem \& Can (2015). It was composed of 20 items divided into four (4) dimensions - acquiescent, quiescent, prosocial, and opportunistic silence. The Cronbach coefficient of the modified scale was 0.93 which was found to be above the acceptable level (.70) recommended by Nunnally \& Bernstein (1994).

The second part was also modified from the scale of Jaros (2007) on organizational commitment which was divided into three (3) indicators - affective, continuous and normative commitment with eight (8) statements each. The Cronbach coefficient of the modified scale was 0.79 which was found to be above the acceptable level (.70) recommended by Nunnally \& Bernstein (1994).

Lastly, the questionnaire of Bang \& Reio (2017) which was originally derived from Maslach Burnout Inventory (1996) was also modified in measuring the level of job burnout of the regular government employees. It was composed of 15 items divided into three (3) dimensions exhaustion, cynicism, and professional efficacy. The Cronbach coefficient of the scale was 0.84 which was found to be above the acceptable level (.70) recommended by Nunnally \& Bernstein (1994).

\section{Method of Data Analysis}

The data gathered in the study were analyzed using statistical tools such as Mean and Spearman's Rank-Order Correlation or Spearman rho. Mean was used in ascertaining the level of employee silence in terms of acquiescent, quiescent, prosocial and opportunistic silence, organizational commitment in terms of affective, continuance and normative commitment and employee's job burnout in terms of exhaustion, cynicism, and professional efficacy. Spearman's Rank-Order Correlation (Spearman rho) was used to determine if there is a significant relationship between employee silence, organizational commitment, and job burnout of the regular employees. In reference with the account of Creswell (2008) on educational research, Spearman rho was the most appropriate correlation tool for the study since the three (3) constructs were measured through a five-point Likert type scale and treated not as interval data, but ordinal data as equality of variance was not established between each value on the scale.

\section{RESULTS AND DISCUSSION}

This chapter presents the collated and analyzed data to draw empirical explanation of the constructs that are examined in this research. It is divided into three (3) separate sections. The first section exhibits the descriptive analyses of the three (3) constructs investigated in this study where each is divided according to its dimensions. The second section shows the correlation analysis on employee silence, organizational commitment, and job burnout. The last section displays the intervention program that is recommended by the researcher to address the issues identified on the job burnout of the employees of the selected local government units in district three (3) of Cotabato.

\section{Respondents' Employee Silence}

Employee silence is an organizational behavior defined as "withholding relevant or confidential information, 
knowledge or concerns of work-related type" which was seen by several authors as a hindrance to the growth of the organization since it impedes the flow of valuable ideas (Adamska \& Jurek, 2017). What is worse is it fails to address ethical transgressions that persist in the organization and increases the employees' stress or makes them feel depressed (Morrison, 2011; Morrison \& Milliken, 2000). Moreover, employee silence is conceptualized as multifaceted with four (4) dimensions which comprise acquiescent silence (futility and resignation based), quiescent silence (fear and anger based), prosocial silence (unselfish and supportive based) and opportunistic silence (self-interest based) (Pinder \& Harlos, 2001). It is on these dimensions that employee silence was investigated by the researcher.

Table one (1) presents the overall level of employee silence in terms of acquiescent, quiescent, prosocial, and opportunistic silence of the regular employees in the selected local government units in District three (3) of Cotabato province.

The research disclosed that regular employees in the selected local government units in District three (3) experienced a moderate level of employee silence at work $($ Mean=3.142). This implies that they were impartial on sharing their inhibition from expressing genuine information, ideas, opinions, or concerns about matters relating to their job and organization.

The general finding resonated the results in every local government unit wherein a moderate degree of employee silence was observed in Kabacan (Mean=3.007), Matalam $($ Mean=3.165), and Carmen $($ Mean=3.256). Nevertheless, the findings of the research do not fully corroborate with the qualitative studies conducted by Milliken, Morrison \& Hewlin (2000). In their research, $85 \%$ of the managers and professionals who participated in their study were revealed to withhold critical organizational information. Their respondents are full-time employees who work in various industries which comprise news media, consulting, advertising and financial services. The difference between the general results of the study and their research findings simply implies that the degree of observance of employee silence among employees varies in the private and public sectors.

Furthermore, it was verified that the local government unit of Carmen ranked the highest in the observance of employee silence among its regular employees with an interpretation of moderate. This result was specifically attributed to the moderate level of acquiescent silence, quiescent silence, prosocial silence, and opportunistic silence observed among its regular employees. Also, it was interesting to note that of all the dimensions of employee silence observed among the regular employees of the local government unit of Carmen, quiescent silence was the most highly observed, while opportunistic silence was the least observed. It was also reported in the study prosocial silence was more highly committed by the regular employees than acquiescent silence.

Secondly, the study found out that the municipality of Matalam ranked next after Carmen in the observance of employee silence among its regular employees with an interpretation of moderate. This finding was elucidated by the moderate level of acquiescent silence, quiescent silence, prosocial silence, and opportunistic silence ascertained among its regular employees. Similar to the results ascertained in Carmen, it was remarkable to note that of all the dimensions of employee silence, quiescent silence was the most highly observed, while opportunistic silence was the least observed in Matalam. Moreover, it was divulged in the study that prosocial silence was more highly experienced by the regular employees than acquiescent silence.

Meanwhile, it was also divulged in the study that employee silence was least observed among the regular employees of the local government unit of Kabacan with an interpretation of moderate. This result was explicated by the moderate level of acquiescent silence, quiescent silence, prosocial silence, and opportunistic silence ascertained among its regular employees. Contrary to the results drawn in Carmen and Matalam, it was noticeable that of all the dimensions of employee silence, prosocial silence was the most highly observed, while opportunistic silence ranked the lowest in Kabacan. It was also important to note that acquiescent silence was more highly observed among the regular employees than quiescent silence.

In synthesizing the results, it was evident in the study that prosocial silence was the most highly observed dimension among the regular employees in general although quiescent silence ranked the highest in the local government unit of Matalam and Carmen. Based on the data gathered, the prosocial organizational silence observed among the regular employees was mainly attributed to their motive of (a) protecting their coworkers and not to put them in a tight spot, (b) not wanting to hurt the feelings of their colleagues or superiors, and (c) not to be seen as person complaining about their coworkers to the management since it was on these areas where prosocial silence was most highly observed.

To further illuminate the finding, the researcher purposely reflected from the definitions of the previous researchers in the field about prosocial silence. Adamska \& Jurek (2017) defined prosocial silence as a form of silence that is based on the employee's altruistic personality and 
collaborative intentions towards the organization. Pinder \& Harlos (2001) added that the intention of withholding a very confidential yet valuable information or work-related concerns is to benefit co-workers people or the organization as a whole. Umphress \& Bingham (2011) added that those who are most likely to observe prosocial silence are the employees who have developed "a strong attachment towards the organization, its members or both." It was on these grounds that the prevalence of prosocial silence among the regular employees in the selected local government units in District three (3) of Cotabato province was partly explained: First is the altruistic personality of the regular employees, and second is the type and strength of connection that they have established towards their organization and their colleagues throughout time. However, Umphress \& Bingham (2011) pointed out that although the intention of silence was selfless and cooperative, prosocial silence also deteriorates the integrity of an organization as it conceals the ethical transgressions of its management or employees.

Table 1. Respondents' Employee Silence

\begin{tabular}{|c|c|c|c|c|c|c|c|c|}
\hline \multirow[b]{2}{*}{ Variables and Dimensions } & \multicolumn{2}{|c|}{ KABACAN } & \multicolumn{2}{|c|}{ MLATALAM } & \multicolumn{2}{|c|}{ CARMIEN } & \multicolumn{2}{|c|}{ OVERALL RESULTS } \\
\hline & Mean & Interpretation & Mean & Interpretation & Mean & Interpretation & Mean & Interpretation \\
\hline 1. EMIPLOYEE SILENCE & 3.007 & MODERATE & 3.165 & MODERATE & 3.256 & MODERATE & 3.142 & MODERATE \\
\hline 1.1. Acquiescent Silence & 3.084 & Moderate & 3.268 & Moderate & 3.414 & Moderate & 3.255 & Moderate \\
\hline 1.2. Quiescent Silence & 2.935 & Moderate & 3.475 & Moderate & 3.532 & Moderate & 3.314 & Moderate \\
\hline 1.3. Prosocial Silence & 3.229 & Moderate & 3.354 & Moderate & 3.475 & Moderate & 3.352 & Moderate \\
\hline 1.4. Opportunistic Silence & 2.783 & Moderate & 2.566 & Moderate & 2.603 & Moderate & 2.650 & Moderate \\
\hline
\end{tabular}

Legend:

Mean Scale
$4.50-5.00$
$3.50-4.49$
$2.50-3.49$

Interpretation

Very high level

High level

Moderate level

Mean Scale
$1.50-2.49$
$1.00-1.49$

Interpretation
Low level

Very low level

\section{Respondents' Organizational Commitment}

The importance of organizational commitment is unquestionable in any organization whether a public and private organization. It was seen as an important indicator of employee retention (Steel, Griffeth, \& Hom, 2002). Additionally, a plethora of research concluded that it is significantly associated with job satisfaction (Lok \& Crawford, 1999). Mowday, Steers \& Poter (1998) defined organizational commitment as the depth of identification and involvement that an individual has with his organization that is unique to him. Kord, Yazdany, \& Bojd (2011) referred it to the "degree of attachment of an individual to the goals, values and vision of the organization he members with." In simplest sense, organizational commitment is the bond that the members have with their organization.

Studying organizational commitment as a multidimensional construct was advanced by Meyer \& Allen (1997). As suggested, this construct was formed by three (3) components - affective (commitment based on emotional attachment), continuance (commitment based on perceived cost of separating) and normative commitment (commitment based on perceived obligation towards the organization). It is on these dimensions that organizational commitment was investigated by the researcher.

Table two (2) exhibits the overall level of organizational commitment in terms of affective, continuance, and normative commitment of the regular employees in the selected local government units in District three (3) of Cotabato province

The study determined that regular employees in the selected local government units in District three (3) shared a moderate level of organizational commitment towards their organization (Mean=3.309). This implies that they were impartial about developing a strong bond towards their organization, especially on identifying themselves as a part of their organization and holding an obligation to stay in the organization primarily because their work is very important to them.

Moreover, the general finding resonated the results in every local government unit wherein a moderate degree of organizational commitment was found in Kabacan (Mean=3.157), Matalam (Mean=3.353), and Carmen $($ Mean=3.417). Likewise, the result showed a slight variation with the findings of Nacpil \& Lacap (2018) among the employees of government agencies in Region III, Philippines. In their research, a high level of organizational commitment in all of the domains of organizational commitment was found among their respondents. Nevertheless, both studies corroborated that government employees in the Philippines, particularly in the selected 
local government units in District three (3) of Cotabato province and Region III have demonstrated a connection and sense of belongingness with their organization.

Furthermore, it was divulged in the study that the municipality of Carmen was the most notable in the observance of organizational commitment among its regular employees with an interpretation of moderate. This finding was specifically attributed to the moderate level of affective commitment, continuance commitment and normative commitment shared by its regular employees towards their organization. Also, it was unveiled that of all the dimensions of organizational commitment, continuance commitment was the most highly observed dimension by the regular employees. Additionally, it was enthralling to discover that affective and normative commitment were equally observed by the regular employees at work. Moreover, the study unveiled that the municipality of Matalam ranked second in the observance of organizational commitment among its regular employees with an interpretation of moderate. This result was explained by the moderate level of affective commitment, continuance commitment and normative commitment shared by its regular employees towards their organization. It was also found out that the regular employees of Matalam have a higher level of affective and normative commitment than continuance commitment at work.

Lastly, the research determined that organizational commitment was least shared at work by the regular employees of the local government unit of Kabacan with an interpretation of moderate. This finding was ascribed to the moderate level of affective commitment, continuance commitment and normative commitment shared by its regular employees to their organization. Additionally, it was reported that the regular employees of Kabacan have a higher level of normative and continuance commitment than affective commitment at work.

In summarizing the finding, it was surprising that the result on the most highly shared dimension of organizational commitment by the regular employees differs in every local government unit although normative commitment was the most highly shared among the three (3) dimensions in general.

Table 2. Respondents' Organizational Commitment

\begin{tabular}{|c|c|c|c|c|c|c|c|c|}
\hline \multirow[b]{2}{*}{ Variables and Dimensions } & \multicolumn{2}{|c|}{ KABACAN } & \multicolumn{2}{|c|}{ MATALAM } & \multicolumn{2}{|c|}{ CARMEN } & \multicolumn{2}{|c|}{ OVERALL RESULTS } \\
\hline & Mean & Interpretation & Mean & Interpretation & Mean & Interpretation & Mean & Interpretation \\
\hline $\begin{array}{l}\text { ORGANIZATIONAI } \\
\text { COMMITMENT }\end{array}$ & 3.157 & MODERATE & 3.353 & MODERATE & 3.417 & MODERATE & 3.309 & MODERATE \\
\hline 2.1. Affective Commitment & 3.044 & Moderate & 3.401 & Moderate & 3.404 & Moderate & 3.283 & Moderate \\
\hline 2.2. Continuance Commitment & 3.153 & Moderate & 3.302 & Moderate & 3.444 & Moderate & 3.299 & Moderate \\
\hline 2.3. Normative Commitment & 3.274 & Moderate & 3.358 & Moderate & 3.404 & Moderate & 3.345 & Moderate \\
\hline
\end{tabular}

Legend:

Mean Scale
$4.50-5.00$
$3.50-4.49$
$2.50-3.49$

Mean Scale
$1.50-2.49$

$1.00-1.49$
Interpretation
Low level
Very low level
Particularly, the study found out that affective commitment was most highly shared by the regular employees in Carmen, continuance commitment in Matalam, while normative commitment in Kabacan granting a moderate interpretation in the three (3) dimensions.

Meanwhile, even though the finding on the most highly observed dimension of organizational commitment differs in every local government unit, normative commitment was found to be the most predominant dimension of organizational commitment shared by the regular employees in general. The prevalence of normative commitment in the three (3) local government units was primarily explained by the following descriptors: (a) Their belief that loyalty is important making them feel a sense of moral obligation to remain, (b) things were better in the days when people stayed in one organization for most of their careers, (c) the value of remaining loyal to one organization, and (d) people these days move from company to company too often. In this light, the study implied that the normative commitment that was found among the regular employees was due to how they value loyalty at work. In fact, their belief on the significance of loyalty established a sense of moral duty among themselves to remain in their organization for most of their careers which then led to developing normative commitment towards their organization.

\section{Respondents' Job Burnout}

When people think of job burnout, they usually label it as a negative experience that deteriorates employee 
performance. Job burnout is defined as a prolonged stress syndrome that is experienced by individuals at work (Maslach, 2004). Among the present studies, the most widely used conceptualization of job burnout was developed by Maslach (Bianchi, Truchot, Laurent, Brisson, \& Schonfeld, 2014). In her model, she characterized job burnout as a multifaceted construct formed by exhaustion, cynicism, and professional inefficacy.

Within the model of Maslach, exhaustion happens when employees experience an overextension and depletion of their mental and physical capital due to their job's excessive demands. Since there is no chance for renewal of energy, employees feel that they are shattered an unable to face another day at work. On the other hand, cynicism - the second dimension of job burnout represents the interpersonal feature of burnout. Cynicism occurs as a result overloaded exhaustion leading employees to develop an adverse and hostile attitude against their job. Employees who fell into this pit lose their vision of idealism at work. Professional inefficacy is the last dimension proposed by Maslach in her model. This component transpires when employees feel incompetence and reduced productivity at work. Bianchi, Truchot, Laurent, Brisson, \& Schonfeld (2014) added that sense of inefficacy at work persist when people chronically consider anything they do as wrong. The danger in this dimension is that people who continuously feel that they are unable to do their job well due to the perceived incompetence at work may result to personally imposed failure in their job. It is on the idea of Maslach (2004) on job burnout that the study investigated it as a multifaceted construct.

Table three (3) shows the overall level of job burnout in terms of exhaustion, cynicism and professional inefficacy of the regular employees in the selected local government units in District three (3) of Cotabato province. The study determined that regular employees in the selected local government units in District three (3) experienced a moderate level of job burnout at work since they just encounter it sometimes (Mean=2.934). This implies that they sometimes feel that they are emotionally and physically drained at work, detached from their work, and incompetent and inefficient in accomplishing a certain task. Besides, the finding resonated with the results in every local government unit wherein a moderate degree of job burnout was observed in Kabacan (Mean=2.880), Matalam (Mean=3.092), and Carmen (Mean=2.830).

Moreover, the study found out that the local government unit of Matalam ranked the highest on the experience of job burnout among its regular employees with an interpretation of moderate. This finding was ascribed to the moderate level of exhaustion, cynicism and professional inefficacy experienced by its regular employees at work. Also, it was significant to point out that the regular employees of Matalam experienced a higher level of exhaustion and cynicism than professional inefficacy.

Secondly, the study revealed that the local government unit of Kabacan ranked next to Matalam on the experience of job burnout among its regular employees with an interpretation of moderate. This result was credited to the moderate level of exhaustion, cynicism and professional inefficacy experienced by its regular employees at work. Furthermore, it was noticeable among the data collated that the regular employees of Kabacan experienced a higher level of exhaustion and cynicism than professional inefficacy.

Lastly, it was explored in the research that job burnout was least experienced at work by the regular employees of the local government unit of Carmen with an interpretation of moderate. This finding was imputed to the moderate level of exhaustion, cynicism and professional inefficacy experienced by its regular employees at work. Similar with results in Kabacan and Matalam, it was observed that the regular employees of Carmen experienced a higher level of exhaustion and cynicism than professional inefficacy.

In amalgamating the results in every local government unit, a similar finding was explored in all the selected local government units indicating that exhaustion was the most predominant dimension of job burnout experienced by the regular employees leaving cynicism as the second and professional inefficacy as the least observed. The results were further explained in the study of Maslach, Schaufeli, \& Leiter (2001) - the pioneering researchers in the field. They explicated that exhaustion is the fundamental feature of job burnout. They also said that when people describe their experience of burnout, they most often refer it to their experience of exhaustion. Accordingly, exhaustion is the most reported component of job burnout, and this had led some to devalue cynicism and professional inefficacy considering them "incidental and insignificant." Moreover, they verified through a series of quantitative and qualitative studies that exhaustion is a contributory element that prompts people to emotionally and cognitively distance themselves. Cynicism and professional inefficacy are just secondary features of job burnout induced by excessive stress at work - the chief characteristic of exhaustion. Furthermore, the degree of exhaustion that the regular employees have experienced in general was primarily grounded to (a) their feeling of being emotionally drained from work, (b) feeling used up at the end of the workday, and (c) their account that working all day was really a strain for them since it was on these areas where exhaustion was predominant among the regular employees. 
Table 3. Respondents' Job Burnout

\begin{tabular}{|c|c|c|c|c|c|c|c|c|}
\hline & \multicolumn{2}{|c|}{ KABACAN } & \multicolumn{2}{|c|}{ MATALAM } & \multicolumn{2}{|c|}{ CARMEN } & \multicolumn{2}{|c|}{ OVERALL RESULTS } \\
\hline Variables and Dimensions & Mean & Interpretation & Mean & Interpretation & Mean & Interpretation & Mean & Interpretation \\
\hline JOB BURNOUT & 2.880 & MODERATE & 3.092 & MODERATE & 2.830 & MODERATE & 2.934 & MODERATE \\
\hline 3.1. Exhaustion & 2.984 & Moderate & 3.279 & Moderate & 3.010 & Moderate & 3.091 & Moderate \\
\hline 3.2. Cynicism & 2.887 & Moderate & 3.113 & Moderate & 2.803 & Moderate & 2.934 & Moderate \\
\hline 3.3. Professional Inefficacy & 2.771 & Moderate & 2.886 & Moderate & 2.678 & Moderate & 2.778 & Moderate \\
\hline \multicolumn{9}{|l|}{ Legend: } \\
\hline $\begin{array}{c}\text { Mean Scale } \\
4.50-5.00 \\
3.50-4.49 \\
2.50-3.49\end{array}$ & & \multicolumn{2}{|c|}{$\begin{array}{l}\text { Interpretation } \\
\text { Very high level }\end{array}$} & \multicolumn{2}{|c|}{$1.00-1.49$} & \multicolumn{3}{|c|}{ Very low level } \\
\hline
\end{tabular}

\section{Relationship between Employee Silence and Job Burnout}

Table four (4) presents the relationship between employee silence and job burnout of the regular employees in the selected local government units in District three (3) of Cotabato province.

The study found a positive yet very low correlation between employee silence and job burnout ( $\mathrm{rs}=0.038$ ). The direction of relationship between the two (2) variables implied that as the regular employee's silence increases to a certain extent, the job burnout also increases. However, no statistically significant relationship was found between employee silence and job burnout $(\mathrm{p}=0.803)$ indicating that the relationship that existed between the two (2) variables was statistically inaccurate and due to chance. Hence, the study does not reject the H01.

In associating the dimensions of employee silence and job burnout, it was found out that no dimension of employee silence has a significant relationship with any of the dimensions of job burnout.

On the other hand, a negative and very low correlation was found between acquiescent silence and exhaustion ( $\mathrm{rs}=-$ 0.004); a negative and very low correlation was determined between acquiescent silence and cynicism ( $\mathrm{rs}=-0.060$ ); lastly, a positive and low correlation was examined between acquiescent silence and professional inefficacy ( $\mathrm{rs}=-0.324)$.

In addition, a positive yet very low correlation was found between quiescent silence and exhaustion ( $\mathrm{rs}=0.141$ ); a positive yet very low correlation was revealed between quiescent silence and cynicism ( $\mathrm{rs}=0.118$ ); lastly, a negative and very low correlation was verified between quiescent silence and professional inefficacy $(\mathrm{rs}=-0.057)$.

Table 4. Relationship between Employee Silence and Job Burnout

\begin{tabular}{|c|c|c|c|}
\hline \multirow{3}{*}{$\begin{array}{c}\text { EMPLOYEE } \\
\text { SILENCE }\end{array}$} & \multicolumn{3}{|c|}{ JOB BURNOUT } \\
\hline & & $\begin{array}{l}r_{s}=0.038^{n s} \\
p=0.803\end{array}$ & \\
\hline & Exhaustion & Cynicism & Professional Inefficacy \\
\hline $\begin{array}{l}\text { Acquiescent } \\
\text { Silence }\end{array}$ & $\begin{array}{l}r_{s}=-0.004^{n s} \\
p=0.987\end{array}$ & $\begin{array}{l}r_{s}=-0.060^{n s} \\
p=0.832\end{array}$ & $\begin{array}{l}r_{s}=0.324^{n s} \\
p=0.240\end{array}$ \\
\hline $\begin{array}{l}\text { Quiescent } \\
\text { Silence }\end{array}$ & $\begin{array}{l}r_{s}=-0.141^{n s} \\
p=0.616\end{array}$ & $\begin{array}{l}r_{s}=0.118^{n s} \\
p=0.675\end{array}$ & $\begin{array}{l}r_{s}=-0.057^{n s} \\
p=0.840\end{array}$ \\
\hline $\begin{array}{l}\text { Prosocial } \\
\text { Silence }\end{array}$ & $\begin{array}{l}r_{s}=-0.300^{n s} \\
p=0.277\end{array}$ & $\begin{array}{l}r_{s}=-0.324^{n s} \\
p=0.240\end{array}$ & $\begin{array}{l}r_{s}=0.254^{n s} \\
p=0.362\end{array}$ \\
\hline $\begin{array}{l}\text { Opportunistic } \\
\text { Silence }\end{array}$ & $\begin{array}{l}r_{s}=-0.439 \mathrm{~ns} \\
p=0.101\end{array}$ & $\begin{array}{l}r_{s}=-0.419^{n s} \\
p=0.120\end{array}$ & $\begin{array}{l}r_{s}=-0.295 \mathrm{~ns} \\
p=0.286\end{array}$ \\
\hline
\end{tabular}

$\mathrm{ns}=$ not significant at 0.05 level of significance (2-tailed)

Meanwhile, a negative and very low correlation was explored between prosocial silence and exhaustion (rs=0.300); a negative and low correlation was explored between prosocial silence and cynicism (rs=-0.324); lastly, a positive yet very low correlation was discovered between prosocial silence and professional inefficacy $(\mathrm{rs}=0.254)$.
Moreover, a negative and low correlation was verified between opportunistic silence and exhaustion ( $r s=-0.439$ ); a negative and low correlation was verified between opportunistic silence and cynicism ( $\mathrm{rs}=-0.419)$; a positive yet very low correlation was confirmed between opportunistic silence and professional inefficacy 
( $r s=0.295)$. Subsequent with the findings, the study inferred that the correlations found between the dimensions of employee silence and job burnout were all inaccurate and due to some extent of probability since they were found to be insignificant.

The findings of the study opposed the results of Paksirat \& Taheri (2016), Akin \& Ulusoy (2016), and Mahmoud \& Muthana (2018) who determined that all the dimensions of employee silence are significantly associated with job burnout. However, a different result was demonstrated by Knoll, Hall, \& Weigelt (2018) concluding that only acquiescent and quiescent silence have a statistically significant relationship with the depersonalization and emotional exhaustion while prosocial and opportunistic silence do not show a significant association with job burnout.

\section{Relationship between Organizational Commitment and Job Burnout}

Table five (5) reveals the relationship between organizational commitment and job burnout of the regular employees in the selected local government units in District three (3) of Cotabato province.

The study determined a negative and very low relationship between organizational commitment and job burnout ( $\mathrm{rs}=-0.083$ ). This implied that the two (2) variables move in an opposite direction demonstrating that as the regular employee's organizational commitment increases to a certain degree, the job burnout decreases or inversely. Nevertheless, no statistically significant relationship was found between organizational commitment and job burnout $(p=0.587)$ indicating that the relationship that existed the two (2) variables was due to chance. Hence, the study does not reject the Ho2.

In linking the dimensions of organizational commitment and job burnout, the study proved that none of the dimensions of organizational commitment has a significant relationship with any of the dimensions of job burnout.

On the other hand, a positive yet very low correlation was unveiled between affective commitment and exhaustion ( $\mathrm{rs}=0.146$ ); a negative and very low relationship was discovered between affective commitment and cynicism (rs=-0.298); lastly, a positive yet very low linkage was confirmed between affective commitment and professional inefficacy ( $\mathrm{rs}=0.234$ ).

Furthermore, a negative and very low association was disclosed between continuance commitment and exhaustion ( $r s=-0.227$ ); a negative and very low relationship was demonstrated between continuance commitment cynicism ( $r s=-0.082$ ); lastly, a negative and very low link was found between continuance commitment and professional inefficacy ( $\mathrm{rs}=-0.004)$.

Additionally, a positive yet low correlation was found between normative commitment and exhaustion ( $\mathrm{rs}=0.317$ ); a negative and very low correlation was found between normative commitment and cynicism ( $\mathrm{rs}=-0.210$ ); lastly, a positive yet very low correlation was found between normative commitment and professional inefficacy ( $r s=0.261$ ). Subsequent with the findings, the study inferred that the correlations found between the dimensions of organizational commitment and job burnout were all inaccurate and due to some extent of probability since all of them were found to be insignificant.

The results of the research corroborated with the findings of Sarışık, Boğan, Zengin \& Dedeoğlu (2019) who concluded that organizational commitment is negatively linked with job burnout. Similar finding was shown by Hakanen et al. (2008) who indicated that organizational commitment do not predict burnout. Hitam, Zawawi \& Jody added that only affective commitment associates burnout. On the other hand, Tan and Akhtar (1998) determined that one of the dimensions of organizational commitment, particularly the normative commitment had a positive influence on experienced burnout, whereas affective commitment had no significant influence. However, a contradiction to the result of the study was provided by Leiter and Maslach (1988) who indicated that all dimensions of burnout correlate with commitment.

Table 5. Relationship between Organizational Commitment and Job Burnout

\begin{tabular}{|c|c|c|c|}
\hline \multirow{3}{*}{$\begin{array}{l}\text { Organizational } \\
\text { Commitment }\end{array}$} & \multicolumn{3}{|c|}{ JOB BURNOUT } \\
\hline & & $\begin{array}{l}\mathrm{r}_{\mathrm{s}}=-0.083^{\text {ns }} \\
\mathrm{p}=0.587\end{array}$ & \\
\hline & Exhaustion & Cynicism & Professional Inefficacy \\
\hline Affective & $r_{s}=0.146^{\text {ns }}$ & $r_{s}=-0.298^{\text {ns }}$ & $\mathrm{r}_{\mathrm{s}}=0.234^{\mathrm{ns}}$ \\
\hline Commitment & $\mathrm{p}=0.604$ & $\mathrm{p}=0.280$ & $\mathrm{p}=0.401$ \\
\hline Continuance & $r_{s}=-0.227^{n s}$ & $r_{s}=-0.082^{n s}$ & $r_{s}=-0.004^{n s}$ \\
\hline Commitment & $\mathrm{p}=0.415$ & $\mathrm{p}=0.771$ & $\mathrm{p}=0.990$ \\
\hline $\begin{array}{l}\text { Normative } \\
\text { Commitment }\end{array}$ & $\begin{array}{l}\mathrm{r}_{\mathrm{s}}=0.317^{\mathrm{ns}} \\
\mathrm{p}=0.250\end{array}$ & $\begin{array}{l}\mathrm{r}_{\mathrm{s}}=-0.210^{\mathrm{ns}} \\
\mathrm{p}=0.452\end{array}$ & $\begin{array}{l}\mathrm{r}_{\mathrm{s}}=0.261^{\mathrm{ns}} \\
\mathrm{p}=0.348\end{array}$ \\
\hline
\end{tabular}




\section{Proposed Intervention Program}

To make the study more meaningful for the regular employees of the selected local government units in the Cotabato province, the researcher purposely crafted an intervention program that would address the job burnout experiences of the regular employees in the local government unit of Kabacan, Matalam and Carmen. The intervention program was a training designed by the researcher. The training program would specifically create an understanding about the structure of burnout among regular employees which includes its definition, signs and symptoms, dimensions, and individual and institution preventive strategies, develop a sense of work appreciation among them as well as establish a stronger connection with their job and colleague. The objectives of the program were designed to address the exhaustion, cynicism and professional inefficacy that regular employees encounter at work. The program was divided into four (4) phases which comprise the opening program, seminar proper, team building activities, and a closing ceremony. The training designed was attached in the following sections of this research.

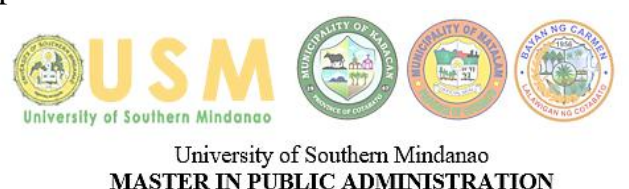

MASTER IN PUBLIC ADMINISTRATION

TRAINING DESIGN OF THE PROPOSED INTERVENIION PROGRAM ON JOB BURNOUT

\section{MUNICIPALITY OF KABACAN, MATALAM, CARMEN}

Objective of the study: Recommend an intervention program that will address the issues or problems identified in the study pertinent to job burnout.

Major issues identified in the study:

- Exhaustion

1. Feeling strain from working all-day

2. Feeling emotionally drained from work

3. Feeling used up at the end of the workday

- Cynicism

1. Becoming more cynical about the contributions of their work

2. Becoming less enthusiastic about work

- Professional Inefficacy

1. Inability to solve the problems that arise at work

2. Uncertainty on being effective in getting things done

3. Unable to feel happy when something was accomplished at work

Title: Seminar-workshop on Job Burnout Prevention \& Employee Formation

Theme: "From Burnout to Balance: Strengthening Workplace Connectivity and Manewvering LGU Employees towards Cultures of Collective and Selfcare"

Participants: Local government employees of the Municipality of Kabacan, Matalam, and Carmen, Cotabato

Date: December 18, 2020 (Saturday)

Venue: Municipal Gymnasium

Proposed budget: PHP 30,000.00 in every municipality 


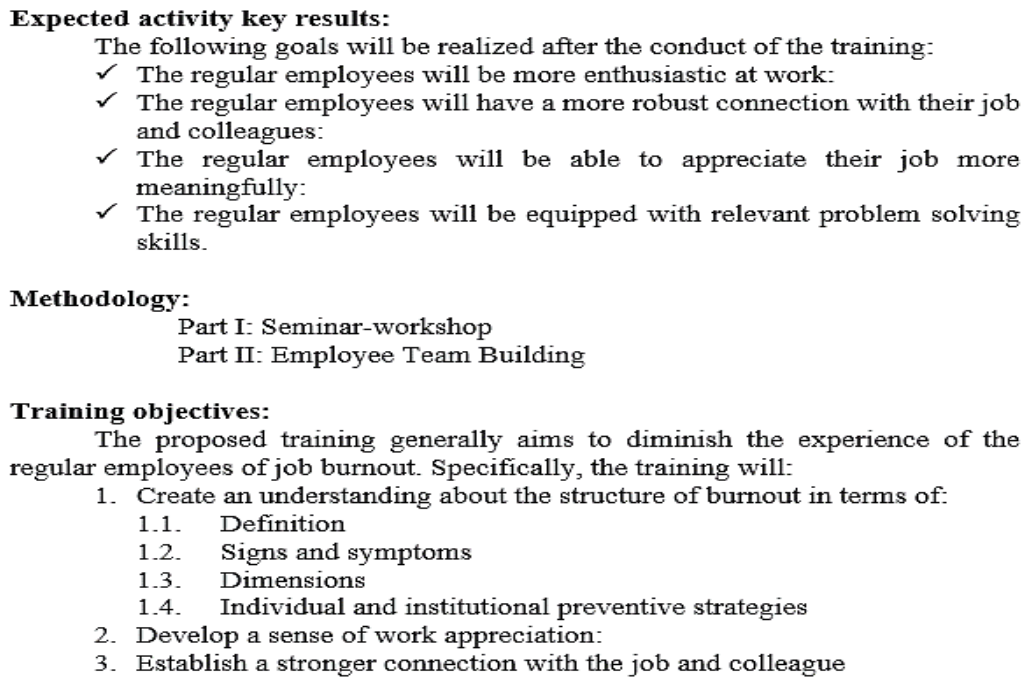

\section{Rationale:}

It is a universal principle in the field of management that the most important asset of any organization is its employees. They are the key to any organizational success. They are the force that fuels all of the activities of the organization. In the study conducted by Nitafan (2020), it was determined that the regular employees of the municipal local government of Kabacan, Matalam, and Carmen experienced certain amounts of job burnout, particularly in terms of exhaustion, cynicism and professional inefficacy. It is a common belief among everyone that job burnout is a negative factor that deteriorates the emotional and physical health of the employees. There are also studies that concluded that job burnout loses the motivation of the employees to work leading to poor employee performance (Sabaah et al. 2012)

In addition to the findings of Nitafan (2020), the problems on job burnout identified issues on exhaustion like feeling strain from working all day, feeling emotionally drained from work, and feeling used up at the end of the workday; issues on cynicism which comprise becoming more cynical about the contributions

of their work, becoming less enthusiastic about work; 1astly, issues on professional inefficacy which include inability to solve the problems that arise at work, uncertainty on being effective in getting things done, and unable to feel happiness when something was accomplished at work.

It is on these research findings that the training was designed to diminish the observance of job burnout among the regular employees of the municipal local government of Kabacan, Matalam, and Carmen, Cotabato.

\section{TRAINING PROGRAM}

Seminar-workshop on Job Burnout Prevention \& Employee Formation Theme: "From Burnout to Balance: Strengthening Workplace Connectivity and Maneuvering LGU Employees towards Cultures of Collective and Self-care."

December 18,2020

Municipal Gymnasium, Kabacan, Matalam, and Carmen, Cotabato

$\quad$ I. Opening Program
Prayer
Philippine National Anthem
Opening Remarks
Inspirational Message
Intermission Number
Statement of Purpose
Introduction of the Resource
Speakers




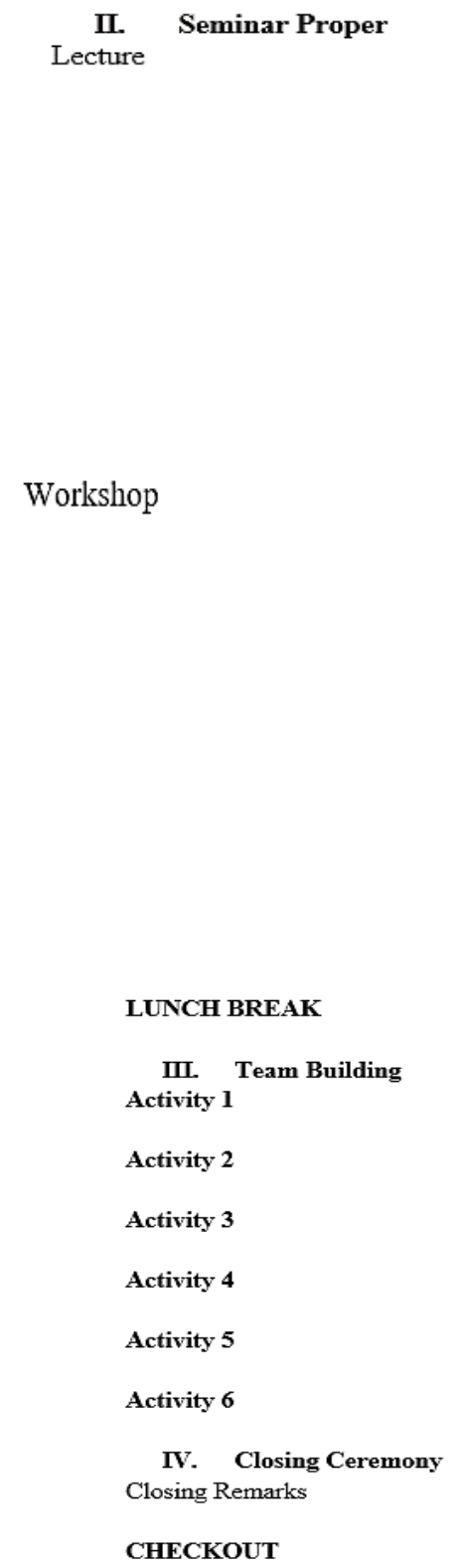

VII. CONCLUSION

The following were the conclusions that were derived from the research findings:

1. The regular employees of the selected local government units in District three (3) experienced a moderate level of employee silence at work; specifically, a moderate degree of acquiescent, quiescent, prosocial, and opportunistic silence was observed among them:

2. The regular employees of the selected local government units in District three (3) shared a moderate level of organizational commitment to their organization; specifically, a moderate degree of affective, continuance, and normative commitment towards their organization was confirmed among them:

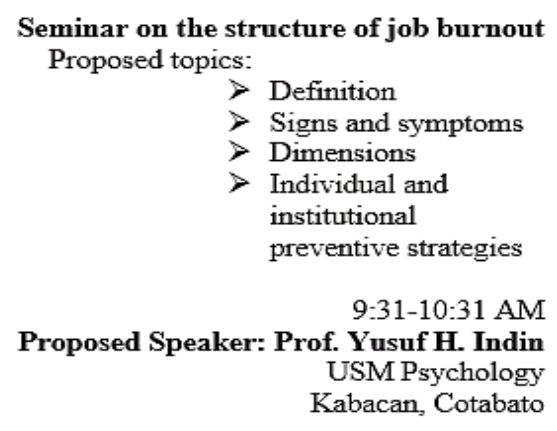

\section{Proposed activity: \\ - Short debriefing \\ - Meaningfulness of public service \\ - Experiences on job burnout \\ - Coping mechanisms rendered to address job burnout}

$10: 32-12: 30 \mathrm{NN}$

Facilitator: Resource Speaker and organizers

3. The regular employees of the selected local government units in District three (3) experienced a moderate level of job burnout at work; specifically, a moderate degree of exhaustion, cynicism, and professional inefficacy was confronted by them in their organization:

4. The study determined a positive yet very low relationship between employee silence and job burnout, but the correlation found between the two (2) variables was proven to be statistically insignificant.

5. The study determined a negative and very low relationship between organizational commitment and job burnout, but the linkage found between the two (2) variables was proven to be statistically insignificant. 
6. The study found out that none of the dimensions of employee silence and organizational commitment was statistically significantly associated with any of the dimensions of job burnout.

\section{RECOMMENDATIONS}

The following were the recommendations of the researcher to address the issues identified in the study as well as advance the current state of research in the field of employee silence, organizational commitment and job burnout:

1. The study recommended that the heads or supervisors of the regular employees in their departments shall give their subordinates a chance to express their ideas at work. They shall listen to their employees' concerns or opinions about the activities of their organization since a considerable degree of acquiescent and quiescent silence were found among the employees. In light with the moderate employee acquiescence ascertained among the respondents, the heads or supervisors shall be open to their proposals or concerns about their work, and an organizational change shall be observed that encourages healthy sharing of knowledge or ideas among them. Moreover, in addressing the moderate degree of employee quiescence observed among the regular employees, the study suggested that the heads or supervisors shall not initiate any adverse or retaliatory steps like dismissing an employee from work whenever someone voices an idea about the organization whether it is positive or not. Furthermore, all regular employees are implied not to be influenced by their fear of being alone as a result of voicing out if the information or knowledge that they keep among themselves is very vital in attaining organizational goals.

2. Although the intention of the employees' prosocial silence was mostly altruistic and cooperative as explicated by numerous studies in the field, the practice of prosocial silence among the regular employees shall not in pursuit of concealing any ethical transgressions at the workplace since such unethical demeanors do not just lead to more serious problems, but also degrade the integrity of the organization.

3. Since the research also discovered a considerable degree of opportunistic silence among the regular employees, it was important to suggest that the regular employees shall not withhold a very relevant information or work-related idea from their superiors or colleagues, especially if it is highly significant in addressing a certain problem or could improve further the current status of the organization since the ascertained opportunistic silence among the respondents was primarily due to concerns that others could take an advantage of their ideas.

4. In strengthening the affective commitment of the regular employees, an intervention program like teambuilding or effective managerial support system towards the employees shall be established to reverse the respondents' inclination of becoming attached with another organization as they were in their organization as well as make them more concerned with the problems existing within their organization since some regular employees were revealed to be apathetic with the problems in their organization.

5. In strengthening the continuance commitment of the employees, the heads or supervisors as well as the Human Resource Management Office shall provide more opportunities to their employees to make them feel that they truly belong in their organization since the study determined that some of the regular employees in the selected local government units have a lot of options to consider leaving their organization.

6. To address the issues identified pertinent to job burnout of the respondents, the researcher highly proposed that the heads or supervisors of the concerned offices as well as the Human Resource Management Office shall use the intervention program recommended in the study as a keystone or guide since it offers a variety of activities that will help the de-escalate the lived experiences of the regular employees on job burnout.

7. To address the limitations of the study, the researcher implied the scholars in the field of organizational sciences to:

7.1. Extend the scope of the study to other provinces or regions and include a larger sample size to confirm whether the findings drawn in this research were also observed in other municipal or city local governments in the Philippines or not:

7.2. Conduct a qualitative study that will explore the lived experiences of the regular employees on employee silence, especially their reasons of silence to draw a more in-depth understanding of the construct:

7.3. Extend the study to the regular employees of the selected private sectors in District three (3) to draw a statistical comparison of the degree of 
employee silence, organizational commitment and job burnout experienced by them at work.

7.4. Conduct a study that correlates job burnout with other constructs in the field of public administration like employee performance, quality of work life and organizational politics to illustrate a bigger picture of job burnout as associated with other constructs.

\section{REFERENCES}

[1] Adamska, K., \& Jurek, P. (2017). Adaptation of the Four Forms of Employee Silence Scale in a Polish sample. Current Issues in Personality Psychology, 5(4), 1-9.

[2] Akın, U., \& Ulusoy, T. (2016). The Relationship between Organizational Silence and Burnout among Academicians: A Research on Universities in Turkey. International Journal of Higher Education, 5(2), 46-58.

[3] Alparslan, A., Can, A., \& Erdem, R. (2015). Reasons for Employee Silence Behavior: Developing and Validating a Scale for Nurses. Hacettepe Journal of Health Administration, 18(2), 183-204.

[4] Argyris, C., \& Schön, D. (1978) Organizational Learning. A Theory of Action Perspective. Addison-Wesley, MA.

[5] Bang, H., \& Reio, T. (2017). Examining the role of cynicism in the relationships between burnout and employee behavior. Revista de Psicologia del Trabajo y de las Organizaciones, 33. 217-227.

[6] Bianchi, R., Truchot, D., Laurent, E., Brisson, R. \& Schonfeld, I. S. (2014). Is burnout solely job-related? A critical comment. Scandinavian Journal of Psychology, 55(4):357-361

[7] Boemah, K.K. (2006). Work wellness in a government organization in South Africa. [Unpublished doctoral dissertation]. Potchefstroom: Northwest University.

[8] Cooke, G., Doust, J., \& Steele, M. (2013). A survey of resilience, burnout, and tolerance of uncertainty in Australian general practice registrars. BMC medical education, 13(1), 1-6

[9] Fishbein, M., \& Ajzen, I. (1980). The prediction of behavior from attitudinal and normative variables. Journal of Experimental Social Psychology, 6, 466-487

[10] Grusky, O. (1996). Career mobility and organizational commitment. Management, 20(1), 59-77.

[11] Hakanen, J.J., Schaufeli, W.B., \& Ahola, K. (2008). The Job Demands- Resources model: A three-year cross-lagged study of burnout, depression, commitment, and work engagement. Work and Stress, 22(3), 224-241.

[12] Knoll, M. \& Hall, R. \& Weigelt, O. (2018). A Longitudinal Study of the Relationships Between Four Differentially Motivated Forms of Employee Silence and Burnout. Journal of Occupational Health Psychology, 24(5), 1-62.

[13] Knoll, M., \& van Dick, R. (2013). Do I hear the whistle...? A first attempt to measure four forms of employee silence and their correlates. Journal of Business Ethics, 113, 349362.
[14] Kumar, D., Alagappar, P., \& Govindarajo, N. (2015). The Impact of Organisational Silence on Job Stress, Organizational Commitment and Intention to Leave among Expatriate Employees. Australian Journal of Basic and Applied Sciences, 9(29), 1-8.

[15] Leiter, M. P., \& Maslach, C. (1988). The impact of interpersonal environment on burnout and organizational commitment. Journal of Organizational Behavior, 9(4), 297-308.

[16] Lok, P., \& Crawford, J. (1999). The relationship between commitment and organizational culture, subculture, leadership style and job satisfaction in organizational change and development. Leadership \& Organization Development Journal, 20(7), 365-374.

[17] Mahmoud, A., \& Muthana, M. (2018). The Effect of Organizational Silence on Burnout: A Field Study on Workers at Jordanian Five Star Hotels. Journal of Management and Strategy, 9(4), 297-308

[18] Mahmoud, A., \& Muthana, M. (2018). The Effect of Organizational Silence on Burnout: A Field Study on Workers at Jordanian Five Star Hotels. Journal of Management and Strategy, 9(3), 114

[19] Maslach, C. (2004). Different perspectives on job burnout. USA: American Psychological Association. http://dx.doi.org/10.1037/004284

[20] Maslach, M., Schaufeli, W.B., \& Leiter, M.P. (2001). Job Burnout. Annual Review of Psychology, 52, 397-422

[21] McDonald D.J., \& Makin PJ. (2000). The psychological contract, organizational commitment and job satisfaction of temporary staff. Leadership Organization Development Journal, 21, 84-91.

[22] McKenna, D. (2015). Challenges the Public Servant could do without. Retrieved March 20, 2020 from https://medium.com.

[23] Meyer, J.P. \& Allen, N. J. (1990). The Measurement and Antecedents of Affective, Continuance and Normative Commitment to the Organisation. Journal of Occupational Psychology, 63, 118

[24] Milliken, F. Morrison, E. \& Hewlin, P. (2003). An Exploratory Study of Employee Silence: Issues That Employees Don't Communicate Upward and Why. Journal of Management Studies, 40, 1453 - 1476.

[25] Morrison, E. W. \& Milliken, F. (2000) Organizational Silence: A Barrier to Change and Development in a Pluralistic World. Academy of Management Review, 25(4), 706-725.

[26] Mowday, R. T., Porter, L. W., \& Steers, R. M. (1982). Employee-Organization Linkages: The Psychology of Commitment, Absenteeism, and Turnover.

[27] Nacpil, L. \& Lacap, J.P. (2018). Job Satisfaction and Organizational Commitment: The Case of Employees of a Government Agency in Region III, Philippines. Journal of Business Management, 1(1), 1-14.

[28] Nuemann, E. (1974). A First Look at Communication Theory. Retrieved November 04, 2020 from http://www.afirstlook.com/docs/spiral.pdf 
[29] Nunnally, J. C., \& Bernstein, I. H. (1994). Psychometric theory (3rd ed.). New York: McGraw-Hill

[30] Oakes, P. J.; Turner, J. C. (1990). Is limited information processing capacity the cause of social stereotyping. European Review of Social Psychology, 1(1), 111-135.

[31] Özsoy S, Ergül Ş, Bayık A. (2004). Examination of a college of allegiance authority employees. Journal of Human Resources and Industrial Relations, 6, 121-117.

[32] Paksirat, V., \& Taheri, A. (2016). Organizational Commitment and Occupational Burnout with Job Performance. Journal of System Management, 4(4), 39-50.

[33] Philippine Statistics Authority. (2019). 2018 Philippine Standard Geographic Code (PSGC), Province of Cotabato (North Cotabato). Retrieved December 27, 2019 from https://psa.gov.ph/classification/psgc/?q=psgc/citimuni/124 700000

[34] Pinder, C., \& Harlos, K. (2001). Employee silence: Quiescence and acquiescence as response to perceived injustice. In G. R. Ferris (ed.). Research in personnel and human resources management, 20, 331-369.

[35] Rothmann S, Jackson LTB, Kruger MM. (2003) Burnout and job stress in a local government: The moderating effect of sense of coherence. South Africa J Industrial Psychology, $29,52-60$

[36] Sabaah, I., Sabaah H., Sabaah S., Akoum H., \& Droubi N. (2012). Burnout among Lebanese nurses: Psychometric properties of the Maslach Burnout Inventory-Human Services Survey (MBI-HSS). Health, 4(9), 644-652.

[37] Sarışık, M. \& Boğan, E. \& Zengin, B. \& Dedeoğlu, B. (2019). The Impact of Burnout on Organizational Commitment: A Study of Public Sector Employees in Turkey. Journal of Global Business Insights, 4(2), 106-118.

[38] Steel, RP \& Griffeth, Rodger \& Hom, Peter. (2002). Practical retention policy for the practical manager. 16. 149162. The Academy of Management Executive 16(2), 149164.

[39] Takeda, F., Yokoyama, E., \& Ibaraki, N. (2005). The Relationship of Job Type to Burnout in Social Workers at Social Welfare Offices. Journal of Occupational Health, 47(2), 119-125.

[40] Tamini, B. Kord, B. Oraei Yazdany, and F. Bakhshi Bojd, 2011, Quality of work life as a function of organizational commitment and job burnout of Government and Private Bank Employees in Zahedan city. The Social Sciences, 6(5), 368-374.

[41] Tan, D. S., \& Akhtar, S. (1998). Organizational commitment and experienced burnout: An exploratory study from a Chinese cultural perspective. The International Journal of Organizational Analysis, 6(4), 310-333.

[42] Umphress, E. E., \& Bingham, J. B. (2011). When employees do bad things for good reasons: Examining unethical proorganizational behaviors. Organization Science, 26, 621640.

[43] Van der Merwe, L. (1984) Work satisfaction among a group of government officials in Pretoria. [Unpublished doctoral dissertation]. Pretoria: Universiteit van Pretoria.
[44] Yau, C., \& Chong, S. (2019). Factors Influencing Job Burnout among Human Resource Employees. International Conference on Management Proceeding, 61(224). 